\title{
How southeastern North Carolina is building more resilient food systems after COVID-19
}

\author{
Julia F. Waity a* \\ University of North Carolina Wilmington \\ Samantha Moser ${ }^{\mathrm{b}}$ \\ University of South Carolina \\ Cara Stretch c \\ Feast Down East
}
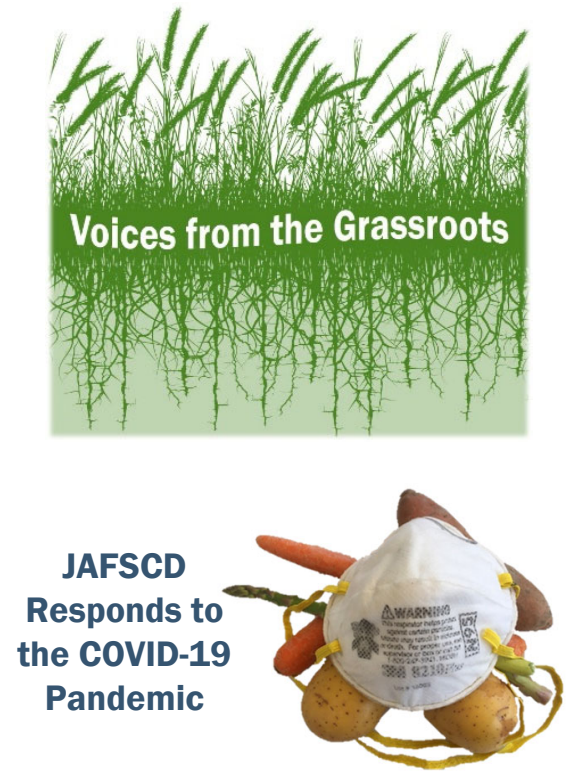

Submitted June 3, 2020 / Published online August 14, 2020

Citation: Waity, J., Moser, S., \& Stretch, C. (2020). How southeastern North Carolina is building more resilient food systems after COVID-19. Journal of Agriculture, Food Systems, and Community Development, 9(4), 191-196. https://doi.org/10.5304/jafscd.2020.094.034

Copyright $(\mathcal{C} 2020$ by the Authors. Published by the Lyson Center for Civic Agriculture and Food Systems. Open access under CC-BY license.

$\mathrm{F}$ east Down East is a regional nonprofit dedicated to creating a healthy, accessible local food system that supports economic growth in southeastern North Carolina. We began as The Southeastern North Carolina Food Systems Program at the University of North Carolina Wilmington (UNCW), founded by Leslie Hossfeld and Rev. Mac Legerton, to address poverty and high job loss in the Southeastern North Carolina region-one of

a * Corresponding author: Julia Waity, Associate Professor of Sociology, University of North Carolina Wilmington; 601 South College Road; Wilmington, NC 28403 USA; waityi@uncw.edu. Dr. Waity is chair of the board of directors of Feast Down East.

b Samantha Moser, PhD Student, University of South Carolina.

${ }^{\mathrm{c}}$ Cara Stretch, Executive Director, Feast Down East. the three major areas of poverty in the state. Now known as Feast Down East, our nonprofit has developed a vast network of partnerships with both private and public agencies in 11 counties.

Today, three main programs make up the heart of our organization: farmer support, produce distribution, and the Local Motive Mobile Farmers Market. Each of these programs is essential to our nonprofit's overall mission. We support local farmers by connecting them with educational opportunities and technical services through either our organization or others in our statewide network. We also work with farmers to promote local food and their products through marketing tactics and consumer education. Alongside these efforts, Feast Down East helps farmers distribute their products through our food hub, providing farmers with reduced distribution costs and added income. To 
encourage new farmers, we have an Emerging Farmers program, which provides classes to a cohort of new farmers to help them successfully expand their farm businesses.

Our food hub is a USDA-designated, GAPcertified center for the processing and distribution of local food products. It eases the burden on small to medium-sized farms in our area when it comes to processing and distributing their goods. On a weekly basis, farmers bring their produce, meat, dairy, and other food products to the food hub to be sold to wholesale buyers in the Wilmington area, including restaurants, grocers, and other businesses. Our food hub is not-for-profit, like all other Feast Down East programs, and relies on donors and grantors to operate.

Finally, our Local Motive Mobile Farmers Market works to support residents of foodinsecure areas by providing access to fresh, healthy local foods. Operating weekly, year-round in underserved areas, we accept SNAP/EBT, debit, and cash and offer a matching program for those using SNAP/EBT to get double the amount of produce for what they are spending.

\section{COVID-19 Adaptations}

The arrival of COVID-19 in our area has presented its own challenges, and we have had to adapt quickly to continue serving those in need of our programs. For health and safety reasons, we began by closing our Local Motive Mobile Farmers Market; however, recognizing the need of the communities we serve, we adapted by delivering free bags of food items to those who are elderly or immune-compromised. Thanks to the help of donations, we were able to deliver 1,262 bags of food, weighing an estimated 6,890 pounds $(3,125$ kilograms), by April 16, 2020, to those most threatened by COVID-19. As the state of North Carolina entered its reopening phases, we ended this program on May 7 and reopened our Local Motive Farmers Markets on May 21. We implemented the following strict health and safety procedures to help serve but also protect not only our team but members of our community: staying six feet apart; making handwashing stations and sanitizing spray available for keys, wallets, phones, and other personal items; allowing just one cus- tomer at a time to approach the market; disinfecting after each payment exchange; and reducing the exchange of cash when possible.

But those receiving our delivery bags were not the only ones in need of help after the COVID-19 pandemic hit. We partnered with many restaurants and foodservice businesses in our area to create a program called FarmsSHARE, which delivers fresh produce to restaurant workers currently unemployed as a result of COVID-19. The boxes are packed and distributed in partnership with New Anthem Brewing and UNCW and funded by the Carolina Farm Stewardship Association (CFSA). The products for this program, and all of our other programs, are coming directly from our local farmers.

Our largest markets for the food hub products are restaurants and schools. As these closed, farmers suddenly did not have anywhere to sell their goods: on the morning of March 17 we saw fairly normal agricultural sales, but almost no sales by the following afternoon. We saw that area residents were minimizing trips to the grocery store to limit their exposure to COVID-19 and realized that we could help farmers by giving them an outlet to sell their produce while at the same time giving locals an opportunity to support local farmers and get fresh produce in a low-risk environment. We created the Farm to Fork Community Supported Agriculture boxes to be sold to community members for US\$35. Purchasers simply drove up to the location of our refrigerated truck, and the box was loaded into their car through contactless delivery. This allowed us to continue providing healthy, local food to the area while ensuring that the farmers are supported. We now have the capacity to sell 100 boxes each week, and we always sell out. We are purchasing products from our farmers for the mobile market, FarmsSHARE, and Farm to Fork CSA boxes. The CSA and FarmsSHARE program support eight to ten small, local farmers on a weekly basis.

\section{Challenges}

When COVID-19 arrived, we faced several challenges. We tried using our current fundraising software to set up the CSA box program, but it just wasn't created for this type of use. The ordering 
and packing process became challenging, so we ended up purchasing a new software system that is specific for food hub sales.

We needed to try several approaches to identify seniors and immune-compromised individuals in need of home delivery for our bags. We asked our partner organizations who work with seniors and the community at large who knew of folks who were at higher risk due to COVID-19 closures and safety concerns. Our mobile market employees, who work very closely with the community and the Wilmington Housing Authority staff, were also able to help us identify recipients. In response to the impact of COVID-19, the Cape Fear Food Council (our local food council) convened foodservice organizations, the hospital, local government, and funders on a weekly call to address community needs. Through these calls, we were able to connect with more organizations that helped us identify vulnerable people in need of the food bags, as well as volunteers who offered to help deliver the bags. Some community members also volunteered to deliver bags.

As restaurants continue to open up, wholesale demand will increase, and farmers are concerned about managing the CSA, FarmsSHARE, and wholesale. Farmers have said that they can grow more but need storage, and livestock farmers need access to processing. We are trying to figure out how to support those needs. One way involves our Farmer Advisory Council. We hosted a Farmer Advisory Council meeting virtually in May to talk through what farmers need in response to the growing demand for local food. We are investigating how we can offer dry, cool storage, and we are partnering with the New Hanover County extension office to raise funds to start a meatprocessing operation.

Our food hub staff members are also continuing to offer technical assistance to our farmers for crop planning and business forecasting. Some of our farmers are already growing products specifically for our CSA boxes.

\section{Planning for the Future}

As restaurants begin to reopen and once again purchase from our food hub, we anticipate that we will keep the CSA program going due to over- whelming community support. Perhaps we will even expand it by hiring someone to manage that program specifically. We are also expanding our mobile farmers market, previously located mainly in public housing neighborhoods, to reach new areas that might need assistance. As people become more interested in and committed to local food, Feast Down East is spending time exploring options to meet the consumer demand and support the needs of the farmers to meet the demand.

COVID-19 has drawn attention to the widespread problems in our current food system. While we see large farmers destroying product, dumping milk, and euthanizing their livestock, our small farmers were able to quickly pivot to ensure that food reached our community. These same small farmers live below the poverty line, struggle to access sufficient healthcare, and are one disaster away from losing everything. They don't have the same resources as large farmers because many programs are not meant to support small farms. Even meat processing poses challenges for small farmers due to the sizes of their orders.

COVID-19 has brought the issue of food insecurity to the attention of a much larger audience. For example, a local newspaper is publishing articles on COVID-19 and food insecurity, interviewing some of Feast Down East's team to learn more. This attention to food insecurity during the pandemic is a good thing, but a lot of the people who are food insecure now were food insecure before COVID-19. The pandemic will increase food insecurity for everyone and make it even more difficult for those who were already food insecure.

Our work in the community during this time has made more people in our region aware of what it is that Feast Down East does. We hope to leverage that support to expand our programs to reach more of those in need in our region. We hope that the community will continue to support locally sourced food in a meaningful way. More specifically, we hope that local markets and small co-op grocery stores will gain customers, restaurants who focus on sourcing food locally will have more patrons, and our small, struggling farmers will have more opportunities to sell their products. 


\section{Resources}

Newspaper article:

- Darrough, M. (2020, May 26). Virtual roundtable: Food insecurity expands its reach due to Covid-19. Port City Daily. https:// portcitydaily.com/local-news/2020/05/26/virtual-roundtable-food-insecurity-expandsits-reach-due-to-covid-19/

Feast Down East:

- About us: https://www.feastdowneast.org/about-us.html

- Farmer support: https://www.feastdowneast.org/farmer-support.html

- Local Motive Mobile Farmers Market:

https://www.feastdowneast.org/local-motive-mobile-farmers-market.html

- Produce distribution: https://www.feastdowneast.org/food-hub-distribution.html 